\title{
Travelers Impact and Consequences of Digitally Connected or Disconnected in Indian Tourism
}

\author{
Srishti Upadhyay, Abhishek Mishra \\ Department of Rural Management, School of Management Studies, Baba Saheb Bhirao Ambedkar University, Lucknow, India \\ Email address: \\ upadhyay.srishti03@gmail.com (S. Upadhyay), abhibbau@gmail.com (A. Mishra) \\ To cite this article: \\ Srishti Upadhyay, Abhishek Mishra. Travelers Impact and Consequences of Digitally Connected or Disconnected in Indian Tourism. \\ International Journal of Management and Fuzzy Systems. Vol. 3, No. 6, 2017, pp. 80-86. doi: 10.11648/j.ijmfs.20170306.11
}

Received: September 9, 2017; Accepted: October 16, 2017; Published: November 8, 2017

\begin{abstract}
Technological progress and tourism have worked in the wheel for several years. the property is that the vehicle that drove the goal of technologically increased tourism experiences forward. This study, through AN beta qualitative analysis identifies the factors that boost and/or distract travelers from getting a digitally increased tourism expertise. Four factors will boost and/or distract travelers from being connected: (1) hardware and package, (2) wants and contexts, (3) openness to usage, and (4) provide and provision of property. The analysis conjointly analyses the positive and/or negative consequences that arise from being connected or disconnected. A Connected/Disconnected Consequences Model illustrates 5 varieties of positive and/or negative consequences: (1) handiness, (2) communication, (3) info obtainability, (4) time consumption, and (5) supporting experiences. a much better understanding of the role and consequence of property throughout the trip will enhance mortal expertise.
\end{abstract}

Keywords: Technology, Connectivity - During-Trip Stage, Unplugging - Selective, Unplugging - Social Wi-Fi

\section{Introduction}

Connectivity has become such an important technological development that innovatively comes like Facebook's star supercharged drone (see: http://www.internet.org) or Google's balloon supercharged technology (see: http://www.google.com/loon) are being developed to deliver property even within the most remote areas around the world. The tourism sector is usually thought-about to be AN data intense business (Fotis et al. 2012). Therefore, it's necessary to grasp however technology, along with online property, has essentially reshaped the distribution of data (Buhalis and Law 2008) and therefore the means individuals expertise their travel (Neuhofer et al. 2014). For this reason, many researchers and developers have undertaken the challenge to find or manufacture a chunk of labor to fuse technology with traveler experiences (e.g. Wang et al. 2012; Berger and Paris 2013; Hannam et al. 2014; Neuhofer et al. 2015; Wang et al. 2014; Paris et al. 2015).

Try and visualise a person WHO is near to lead off a journey. As he makes his thanks to the flying field, he listens to music on Spotify, keeps socially updated on Facebook, and completes the web arrival for the flight. He boards the flight with a laissez passer that was retrieved on a smartwatch, arrives at the destination, and books a ride with Uber to the town center. when checking-in at the building, the visitor selects and books an eating house through Trip authority, then navigates to that exploitation Google Maps. Once the food arrives, he captures a photograph and uploads it on Instagram and Facebook, shares his location and writes a brief insight on Twitter, chats on WhatsApp and reviews the eating house on Trip authority. Google Now, suggests a listing of attractions within the neighborhood that he may wish to go to. Once within the suggested attraction, he opens optical instrument and shares a live stream of the read with individuals from all around the world. Current technology provides of these activities to be performed effectively and with efficiency. though this, by no suggests that, represents however all travelers use technology, it illustrates practical prospects that users will probably operate.

The ever-increasing body of labor on however data and communication technologies (ICTs) influence travellers throughout their trip has typically targeted on however digital 
media, software, and devices will increase communication, gather data, co-create, and improve experiences (e.g. Buhalis and Amaranggana 2013; Buhalis and Foerste 2013, 2015; Wang and Fesenmaier 2013; Lamsfus et al. 2015). On the alternative finish of the spectrum, there's additionally rising analysis on the elicited experiences and tensions ensuing from disconnection or unplugging from technology (e.g. Pearce and Gretzel 2012; Paris et al. 2015; Germann Molz and Paris 2015).

This study aims to explore the factors that boost or distract the employment of property throughout a visit and therefore the consequent positive and/or negative consequences of being connected and/or disconnected. The outcomes of those findings supply strategic implications for tourism marketers, and a distinct perspective for researchers.

\section{Review of Literature}

The accumulation of data and online content shapes the tourism expertise in 3 completely different stages: pre-trip, during-trip, and post-trip (Hjalager and Johannes Vilhelm Jensen 2012). The events that occur before the trip (e.g. planning), during (e.g. at destination) and once the trip (e.g. recollection) frame one's individual subjective analysis and undergoing of a travel expertise (Tung and Ritchie 2011). During the design method, tourists use info search to get concepts, rummage around for alternatives, and facilitate avoid places that don't interest them (Xiang and Gretzel 2010). Through reading on-line reviews, travellers gain a clearer image of what to expect, increase their confidence in deciding and cut back the chance of satisfaction disconfirmation (Xiang and Gretzel 2010; Jun et al. 2012). At the post trip stage travellers socialize, communicate, share experiences, facilitate others, and reconstruct their reminiscences of the trip by mistreatment social media (Jun et al. 2012; Wu and Pearce 2016). In doing thus, travellers enter an \{mental imagery | imagination | imaging | imagery | representational method process that has the potential to change their satisfaction level of their previous trip (Jun et al. 2012).

\subsection{Technology and Property Increase Experiences}

Online communication is more and more difficult the standard read wherever tourists manage to disconnect themselves from their home and go in a doubtless rewardful, life-changing or difficult area (Pearce 2011). This notion of movement between 2 distant worlds has been substituted with the thought of 'digital elasticity' (Pearce 2011). modern travellers explore the identity and also the world of others whereas remaining electronically connected with their home world (Pearce and Gretzel 2012). the thought of disconnection while travel has given thanks to the modern travellers' world wherever they paradoxically build systematic efforts to stay in contact with friends and family (White and White 2007). Constant property enhances the sense of obligation for travellers to retain an equivalent level of presence, attention, and intimacy with their friends and relatives (Pearce and Gretzel 2012; Germann Molz and Paris 2015).

As a results of raised use of technology, tasks that were antecedently consummated within the pre-trip and post-trip stages area unit currently being consummated throughout the consumption stage (Wang and Fesenmaier 2013; Wang et al. 2014).

As a result, Wi-Fi, even with its limitations (i.e. lack of coverage), is commonly the popular technique of association (Gass and Diot 2010). Wi-Fi will offer intermittent high bursts of information retrieval at an occasional or free price, whereas roaming offers the continuous property with low knowledge rates and comparatively high prices (Gass and Diot 2010).

Third party applications area unit able to gain access to knowledge that is already obtainable on the user's profile: access to basic info (e.g. user name or email address), personal info (e.g. gender, position, residence, friend list), created content (e.g. images, videos, standing updates), knowledge from doubtless nonconsenting users (e.g. friends), and also the writing permissions for RPs to share content on the users' social network (Vapen et al. 2015).

Nonetheless, users' considerations concerning the loss of privacy and security vulnerability of social logins area unit usually a consequence of a poor understanding of however the system works (Gafni and Nissim 2014). whereas there's increasing literature on social logins (e.g. Sun et al. 2013; Vapen et al. 2015), there's a big lack of analysis on Social Wi-Fi, and particularly travellers' perception of this property enabler.

\subsection{Unplugging and Disconnection}

The inability to attach online is either one's own personal call, or results of inadequate infrastructure (Paris et al. 2015). The absence of extremely acquainted sensory inputs and disconnection creates technology-induced tensions to some (Pearce and Gretzel 2012) however a relief for others (Germann Molz and Paris 2015). Pearce and Gretzel (2012) established four sorts of technology-induced tensions in dead zones areas: (1) social communication tension, (2) work communication tension, (3) security escape tension, and (4) immediacy connectedness tension. Technological dead zones produce 'social communication tension' as travellers area unit unable to fulfill the standard social expectation to be unceasingly connected and in constant communication. At an equivalent time, dead zone areas offer the human a prospect from this continuous has to be compelled to be on-line. the actual fact that one cannot receive or send communication in dead zone areas offers an honest justification for the death of virtual interaction.

While dead zone areas would possibly produce work anxiety, at an equivalent time this disconnection provides a relief from responsibilities because it creates a compelling excuse to not listen to Figure communication. the lack to for travellers to report their well-being to others provokes a security tension to some. On the opposite hand, being disconnected arouses a way of journey, naturalness, and 
freedom to actually break loose society. Technological dead zones encourage travellers to specialize in the instant and to stimulate skills that technology would possibly generally replace.

Ultimately, the extent of reaction towards being unplugged depends on the first intent of the trip, the perceived want of staying connected and also the level of management and selection over the disconnection (Paris et al. 2015). In follow, Paris et al. (2015) argue that there can be promoting the potential for disconnection as long because it is that the travellers' option to be unplugged. If the human is originally aware that he/she are in a dead zone space, or need to be in a dead zone space, then the extent of hysteria can drop thanks to the notice and also the preparation that is completed beforehand to touch upon the ultimate disconnection. Arguably, whereas networking technologies produce ways that of being just about along, it conjointly creates new needs for distance and new ways that of disconnecting (Germann Molz and Paris 2015). Indeed, poet et al.'s (2016) study on travellers staying in campsites shows that tourists don't seem to be perpetually connected, and up to fifty p.c of them have some need to disconnect. The influences and consequences of being digital.

\section{Methodology}

The nature of the study involves problems that require being explored deeply. For this reason, the associate degree exploratory qualitative analysis was meted out by conducting face-to face semi-structured interviews. the first analysis used a purposive sample since it represents a good technique for pre-determined criteria for the choice of participants (Bryman 2008).

Before conducting the interviews, careful thought was taken in reference to setting and developing the queries. The queries were unbroken taciturn and beneath one sentence with the aim to be unambiguous and targeted. Moreover, the queries were worded to be understood simply by victimisation everyday language.

The term 'informal experts' doesn't relate to experience and formal data from the knowledgeable purpose of reading, but rather, it focuses on personal interest and also the interviewees' sensible grasp of the variety of functionalities of on-line property and quality devices (Line et al. 2011).

The sixteen participants UN agency accepted to participate in the study were interviewed between twenty-sixth of the Gregorian calendar month and $8^{\text {th }}$ of July 2017. 3 pilot interviews were conducted within the state before execution the ultimate interviews. The participants of the pilot interview were asked to be as important as doable and description any queries that

Predetermined set of Questions to guide the interview

1. what quantity worth does one place on social media and net in your life?

2. however dependent on property square measure you throughout your trip?
3. What square measures the activities that you decide to use property throughout your trip?

4. are you able to list associate degree expertise wherever you desired or needed to be on-line however it had been not available?

5. are you able to list experiences wherever you desired or needed property and it had been available?

6 . If any, what square measure the most positives of being connected to your tourer experiences?

7. If any, what square measure the most negatives of being connected to your tourer experiences?

8. what's your perspective or feeling towards Wi-Fi services that use social logins?

9. however would your vacation are totally different if you had no property at all?

seemed ambiguous or not comprehensible. As a result, a number of the predefined queries had to be redeveloped to be clearer for the interviewees.

The state beach was selected as a perfect location to get experiences of international travellers.

Both locals and tourists, once movement, ought to travel on the far side their immediate boundaries to access or leave the country, and so face international enablers and barriers of property.

The Goa Beach Was Selected as an Ideal Location to Obtain Experiences of International Travellers

Both locals and tourists, when travelling, have to travel elsewhere their immediate boundaries to access or leave the country, and thus expression international enablers and barriers of connectivity.

Respondents were recruited through social networks, and verbal advertising. The period of the interviews ranged between fifteen to fifty-two min. Table a pair of shows the sample profile of the respondents. though the participants could seem socio-demographically various, the study wasn't trying to recruit a sample distribution or claiming for generalisability, however to explore the problem of property in an exceedingly method that is transferable to connected studies (Line et al. 2011).

In the 1st section, familiarisation with information concerned transcription of text from the interviews. This section additionally enclosed continuous reading and rereading of the transcriptions to create the initial analysis of the information. within the second section, initial codes were generated to achieve a deeper understanding of the information collected.

The third section enclosed the rummage around for themes by distinguishing codes that were associated with one another. The fourth section of the analysis consisted of a review of the themes. to confirm data was accurately supported and diagrammatical in these themes, the information was taken once more. within the fifth section, themes were outlined and named, whereas guaranteeing that they are doing not become too numerous or too complicated. The sixth and final section concerned the primary analysis and write-up of the report. 
Table 1. Sample profile.

\begin{tabular}{lllll}
\hline Sr. No. & Name & Gender & Nationality & Age \\
\hline 1 & Mahesh & Male & Indian & $20-29$ \\
2 & Sarah & Female & Malaysian & $20-29$ \\
3 & George & Male & Australian & $40+$ \\
4 & Kate & Female & Italian & $20-29$ \\
5 & Jack & Male & Thailand & $30-39$ \\
6 & Sarah & Female & Italian & $20-29$ \\
7 & John & Male & Maltese & $30-39$ \\
8 & Chen Bao & Female & Chinese & $30-39$ \\
9 & Michael & Male & Taiwanese & $20-29$ \\
10 & Emily & Female & Italian & $20-29$ \\
11 & James & Male & Maltese & $20-29$ \\
12 & Joanne & Female & German & $30-39$ \\
13 & Ryan & Male & Maltese & $20-29$ \\
14 & Victoria & Female & French & $20-29$ \\
15 & Owen & Male & Maltese & $20-29$ \\
16 & Samantha & Male & Austrian & $20-29$ \\
\hline
\end{tabular}

\section{Factors Influencing Property Increased Expertise}

This study has known each technological and nontechnological reasons that influenced the participants' want for property whereas travel. the buildup of those factors has been classified in four main factors: (1) hardware and code, (2) want and contexts, (3) openness to usage and (4) offer and provision of property. every of those four main factors has underlying options that may boost or discourage web increased experiences (Figure 1)

\subsection{Hardware and Code}

The combination of hardware and code permits property to become, to a precise extent, tangible for users. it's the utilization of devices and their complementary code that enable users to attach to the net and create use of its resources.

\begin{tabular}{|c|c|c|}
\hline$(+)$ Encourage & & (-) Discourage \\
\hline $\begin{array}{l}\text { Devices } \\
\text { Applications }\end{array}$ & Hardware and Software & $\begin{array}{l}\text { Deficiencies of Technology } \\
\text { Offline Applications }\end{array}$ \\
\hline $\begin{array}{l}\text { Solo Traveler } \\
\text { Unfamiliarity } \\
\text { Purpose of travel } \\
\text { (e.g Discovering ) }\end{array}$ & Needs and contexts & $\begin{array}{l}\text { Accompanied Traveller } \\
\text { Familiarity } \\
\text { (e.g Relaxation) }\end{array}$ \\
\hline Actively connected & Accessibilits & selective Unplugging \\
\hline $\begin{array}{l}\text { Available Infrastructure } \\
\text { Social Wi -fi }\end{array}$ & & $\begin{array}{l}\text { self- Imposed total disconnection } \\
\text { Unavailable infrastructure } \\
\text { Lack of knowledge / Trust on } \\
\text { Foreign Service Providers }\end{array}$ \\
\hline
\end{tabular}

Figure 1. Factors that Encourage or discourage use of connectivity.

The respondents used quality devices to realize property, and operated an excess of various computer code to extend the functionalities of their devices. The speed at that info is often retrieved heavily influences the amount of interest in exploitation property to reinforce associated expertise. fashionable technology has enabled users to instantly connect on-line to seek out info, co-create experiences with friends, relatives and/or suppliers, associated consequently become an accompaniment to their trip. whereas hardware and computer code change users to attach on-line, a number of their technical deficiencies will at a similar time convince to be a barrier for the property. As Neuhofer et al. (2015) equally discovered deficiencies of technology for the participants included: short battery life, slow and nonintuitive applications or devices. what is more, offline applications were looked as if it would become additional\} more offered, and therefore reduced the requirement for the travellers to seek out the association. however, few applications are able to perform all of their functionalities whereas offline and users usually have to be compelled to transfer content before utilizing them during a destination.

\subsection{Openness to Usage}

The level of openness to using property throughout movement heavily influences the likelihood of web increased experiences. totally different | completely different\} participants had different views on the amount of escape they wished from their travels. The property, being such associated integral a part of the lifestyle, has become admire an important item during a baggage to some, however to 
others it's additionally become associated emotional and behavioral baggage. those that understand property as a method to reinforce their expertise or the way to stay some association to the life they're briefly deeding, are a lot of possibilities to observe the web increased expertise than those that want to flee from home-both physically and nearly. The study has determined 3 explicit voluntary approaches to connectivity: (1) actively connected, (2) selective unplugging, and (3) voluntary total disconnection

The first approach, actively connected, refers to users United Nations agency want to be connected throughout their trip. Participants with this approach typically wanted to stay socially updated, sustain with any work developments, cocreate their experiences, and notice traveller details and reviews regarding explicit places. Some respondents even admitted that, throughout their travels, they often become even a lot of action than usual on social media. This additionally supports Minazzi and Mauri's (2015) claim that unforgettable travel experiences will increase the number and form of content that travellers' publish on social media.

Selective Unplugging also can visit moments of the day wherever the user consciously decides to prevent exploitation the net, or to limit on-line usage to an exact time of the day:

"When I used to be a bar, I used to be watching places wherever we tend to might go, and so I simply accomplished, why not simply fancy the instant and that I can hunt places before sleeping. you have got to be aware to prevent doing that kind of issue, as a result of I make love while not needing to. I'm aware that typically, I exploit it too much', (James);

\subsection{Provision and Provider of Property}

While participants have totally different choices to property throughout their trip, the flexibility to attach on-line remains beneath the prerequisite of the suppliers of property. Provision and provider of property through appropriate telecommunications infrastructure (data networks, Wi-Fi) permit users to be connected (Neuhofer et al. 2015). the value of property typically discourages travellers from getting a connectivity-enhanced expertise. Preference is commonly given to free $\mathrm{Wi}-\mathrm{Fi}$ hotspots - even with their restricted coverage. Wi-Fi is usually free-to-access and tends to produce quicker and a lot of reliable association than information networks (Gass and Diot 2010). Participants United Nations agency used 3G/4G networks throughout their visits typically restricted their usage to essential activities and avoided bound functionalities (e.g. social networking, viewing multimedia) to limit the number of knowledge downloaded and roaming prices. International mobile info search behaviour is strained by not solely the supply of networks however additionally the value of network access (Dewan and Benckendorff 2013). still, it's necessary to notice that the demolition of roaming charges in Europe in Gregorian calendar month 2017 may modification future usage behaviour because it can change travellers to use their information allowance throughout Europe and therefore facilitating constant property.
"Yeah I exploit Wi-Fi where it is: the building, hostel or edifice or eating place. I'm not attempting to use the $3 \mathrm{G}$ that I actually have as a result of it prices cash and that I don't wish to pay cash once there's Wi-Fi', (Sarah).

The premise behind Social Wi-Fi is that it provides a lot of convenient thanks to access property. a lot of significantly, through Social Wi-Fi, provision of property now not remains a service that is effective entirely for shoppers, however it additionally becomes a product that is equally valuable for suppliers. allowing users to apply Wi-Fi through work in their various social networks permits organisations to extend engagement with customers and to additionally retrieve valuable information. This service permits organisations to own a rare chance to get live insights and to co-create experiences with their shoppers. however, the success of Social Wi-Fi depends on the acceptance and usage of shoppers. Respondents had mixed attitudes towards exploitation Social Wi-Fi and known totally different positive and negative aspects of exploitation this service. Social Wi-Fi was praised for being a lot of convenient and quicker to attach to and additionally avoids parole fatiguebenefits that are the same as the perceived edges of social logins on websites (Sun et al. 2013; Gafni and Nissim 2014).

\subsection{Consequences of Association and Disconnection}

The state of being connected or disconnected obligatory variety of positive and negative consequences on the respondents. Figure a pair of shows 5 kinds of consequences: (1) accessibility, (2) communication, (3) info obtainability, (4) time consumption, and (5) supporting experiences.

\subsection{Accessibility}

Availability refers to the presence of the human within the on-line and physical world. the flexibility to attach on-line provides travellers a chance to take care of association, intimacy, and movement as they perform social interactions on their devices (Germann Molz and Paris 2015). Being offered is very important associated a relief to some however additionally a hindrance to others: once connected there's a present expectation to take care of regular contact as if the human were still reception. This expectation has additionally manifested itself during a kind of addiction wherever users perpetually keep checking for brand new notifications. The psychological feature and behavioral have to be compelled to perpetually check for notification updates are commonly joined to sensible devices (Harwood 2014) The advantage of being disconnected is that it provided the respondents the prospect to actually escape lifestyle and immerse during a destination. whether or not this shake off property is temporal or throughout the complete course of the trip, it offers travellers the chance to depart behind the everyday thoughts and challenges of their lifestyle and immerse themselves in the travel activity or place. however, a degree of contact with "'home"' was still perceived as necessary.

" And I'm about to worry, is my girlfriend about to text American state on the chat app or my family about to chat 
with American state and so I disappear, thus I'm quite distressed that folks \{are $\mid$ ar $\mid$ area unit $\mid$ square American stateasure $\}$ about to worry regarding me. I don't grasp I'm dependent on social media sometimes", (Jack).

\subsection{Info Obtainability}

As tourists still arrange less before moving to a destination (Wang et al. 2014) and have faith in the property to seek out info at the correct time and at the correct moment, info obtainability becomes more and more necessary. One major positive consequence of a web increased expertise is that the unimaginable quantity of data offered (Xiang et al. 2015). Respondents recalled however they used their devices throughout their travels to get help with traveller details, navigation, reviews and instant info. However, one negative consequence is that info is often thus large and careful that now and then it will become overwhelming. It additionally has the flexibility to require away experiences that are otherwise enjoyed otherwise. Disconnection provides a compelling reason to wander around a destination and revel in experiences that are typically created redundant by the property. Some respondents argued that unplanned discoveries ar maybe even a lot of bountied than pre-planned activities. however, their are occasions wherever retrieval of data remains essential. the shortcoming to seek out swift info is one among the most disadvantages of disconnection. Being disconnected provides restricted sources and detail of data. Disconnection and unusualness with a destination could be a combination which will induce frustration and even cause trying moments for travellers once info is required.

"The quantity of data that you simply will get at each moment, every time, in no matter scenario. you create the foremost of the expertise, you are doing not miss anything... whereas after you don't have the web, you're to a small degree lost, and you wander around', (Emily).

\subsection{Supporting Experiences}

The online property is in a position to support users on info, amusement, and communication necessities. property gives travellers a way of security in knowing that any wants are often self-addressed instantly. Minazzi and Mauri (2015) mentioned however tourists cut back the perception of risk through the supply of on-line info and enrich their experiences with instant choices exploitation quality devices. This reduces the traditional stress that arises from briefly living during a totally different and unknown surroundings, typically with its totally different culture, language, norms, particularly once visiting for the primary time. However, this may additionally become prejudicial once travellers overdepend on that, as the property is inconvenient and trying once it's unobtainable. whereas property has the flexibility to assist and increase the private development of travellers, it also can cage the human in his/her own on-line world and miss out on potential learning experiences.

"Not essentially a plus at time as a result of it would distract you, however, overall I believe it's a and as a result of it's a service that's offered there and you ne'er grasp what you may want off the internet', (Mary).

Figure a pair of illustrates however the 5 kinds of consequences will doubtless feature positive and/or negative attributes for each association and disconnection. the implications of being (dis)connected rely on the amount of management over the choice to own association or disconnection, the openness for usage and therefore the context of the human. The positives from being disconnected are amplified if the disconnection is that the traveller's own personal call through obstruction access to property or wittingly movement in unplugged areas. The negatives can intensify if the disconnection wasn't a private call created by the human however was obligatory on him/her. The negative consequences of each association and disconnection are often reduced if the human is in a position (and is allowed to) strike a balance between each approach.

\section{Conclusion}

Connection and disconnection have typically been studied solely in their own various worlds. In doing this, researchers typically unheeded the very fact that travellers ought to normally modify between the 2 states of connections throughout their travels instead of being utterly connected or disconnected. to boot, the influence of technology has typically been determined entirely from a computer code and/or device purpose of reading (e.g. smartphones and wearable technologies) (e.g. Wang and Fesenmaier 2013; poet et al. 2014; Tussyadiah 2014; Wang et al. 2014) however seldom have they specifically focused on the most issue that maximises their functionalities: property.

This analysis aimed to fill this literature gap by understanding the factors that Encourage or discourage property increased experiences and therefore the positive and negative consequences of being connected and/or disconnected. the buildup of those influences was classified in four main factors: (1) hardware and computer code, (2) want and contexts, (3) openness to usage, and (4) offer and provision of property. Travellers' openness to usage is arguably the foremost cogent think about being connected or disconnected. while not the will to get property all the opposite factors which will change web association become futile. Conversely, hardware, software, provision of property become crucial supporting tools once the user wishes to move on-line throughout the trip. afterward, the analysis additionally gave variety of varied experiential consequences of being connected and/or disconnected. The findings recommend that the implications of being (dis)connected mostly rely on the amount of management over the choice to be connected or disconnected, the disposition to use property, the context of the human, and therefore the travellers' willing balance between the 2 opposite states of property The analysis has known 3 totally different approaches to property. Through the novel approach of specializing in each association and disconnection, the study introduced the thought of "selective unplugging", wherever travellers 
conceive to strike a balance on the usage and dependence on the net and its supporting tools. or else, travellers may value more highly to be 'actively connected' throughout their trip, or even observe a 'self-imposed total disconnection'. As a result, businesses seeking to satisfy their customers' wants ought to conceive to perceive the wishes of their target markets, and make sure that they're equipped with the accep'e infrastructure.

These analysis gift findings from a qualitative preliminary analysis. Consequently, the results aren't generalisable, however they supply a solid foundation for additional analysis. thanks to the constraints of the qualitative and purposive sampling approach, a quantitative study will extend this study to check findings on a bigger scale. to boot, future investigations associated with this subject could doubtless concentrate on a variety of areas, including:

1. The extent to that 'selective unplugging' approach is used by travelers.

2. The factors that influence the degree to that 'selective unplugging' approach is employed.

3. The role of Social Wi-Fi within the context of travel and business enterprise.

As technology increased experiences, co-creation, and sensible destinations still emerge and grow (e.g. Buhalis and Amaranggana 2013; Neuhofer et al. 2014, 2015; Buhalis and Foerste 2015), each teacher and marketers have to be compelled to guarantee there's applicable level of infrastructure. Effectively, destinations and organisations have to be compelled to guarantee their telecommunications infrastructure is capable to handle the ever increasing wants of the market.

\section{References}

[1] Berger E, Paris C (2013) Exploring the role of Facebook in reshaping backpacker's social interactions. In: Xiang Z, Tussyadiah I (eds) Information and communication technologies in tourism 2014 [Online]. Springer International Publishing, London, pp 299-312.

[2] Jun S, Hartwell H, Buhalis D (2012) Impacts of the Internet on travel satisfaction and overall life satisfaction. In: Uysal M, Perdue R, Sirgy MJ (eds) Handbook of tourism and qualityof-life research (Online). Springer Netherlands, Houten, pp $321-337$.

[3] Kim J, Fesenmaier D, Johnson S (2013) The effect of feedback within social media in tourism experiences. In: Marcus A (ed) Design, user experience, and usability. Web, mobile, and product design [Online]. Springer, Berlin, pp $212-220$.

[4] Lamsfus C, Martı'n D, Alzua-Sorzabal A, Torres-Manzanera E (2015) Smart tourism destinations: an extended conception of smart cities focusing on human mobility. In: Tussyadiah I, Inversini A (eds) Information and communication technologies in tourism 2015. Springer International Publishing, London, pp 363-375.

[5] Line T, Jain J, Lyons G (2011) The role of ICTs in everyday mobile lives. J Transp Geogr 19(6):1490-1499.

[6] Minazzi R, Mauri A (2015) Mobile technologies effects on travel behaviours and experiences: a preliminary analysis. In: Tussyadiah I, Inversini A (eds) Information and communication technologies in tourism 2015. Springer International Publishing, London, pp 507-521.

[7] Paris C, Berger E, Rubin S, Casson M (2015) Disconnected and unplugged: experiences of technology induced anxieties and tensions while traveling. In: Tussyadiah I, Inversini A (eds) Information and communication technologies in tourism 2015. Springer International Publishing, London, pp 803-816.

[8] Pearce P, Gretzel U (2012) Tourism in technology dead zones: documenting experiential dimensions. Int J Tour Sci 12(2):120 .

[9] Pearce PL (2011) Tourist behaviour and the contemporary world. Channel View, Bristol.

[10] Tung VWS, Ritchie JRB (2011) Exploring the essence of memorable tourism experiences. Ann Tour Res (Online) 38(4):1367-1386.

[11] Tussyadiah I (2014) Expectation of travel experiences with wearable computing devices. In: Zheng X, Tussyadiah I (eds) Information and communication technologies in tourism 2014. Springer International Publishing, London, pp 539-552.

[12] Vapen A, Carlsson N, Mahanti A, Shahmehri N (2015) Information sharing and user privacy in the third party identity management landscape (Online). In: Proceedings of the 5th ACM conference on data and application security and privacy-CODASPY'15, San Antonio 02-04 March 2015. ACM, New York, pp 151-153.

[13] Wang D, Fesenmaier D (2013) Transforming the travel experience: the use of smartphones for travel. In: Cantoni L, Xiang Z (eds) Information and communication technologies in tourism 2013. Springer, London, pp 58-69.

[14] Wang D, Park S, Fesenmaier DR (2012) The role of smartphones in mediating the touristic experience. J Travel Res (Online) 51(4):371-387.

[15] Wang D, Xiang Z, Fesenmaier DR (2014) Adapting to the mobile world: a model of smart phone use. Ann Tour Res 48:11-26.

[16] Wu MY, Pearce PL (2016) Tourism blogging motivations: why do chinese tourists create little "lonely planets"? J Travel Res 55(4):537-549.

[17] Xiang Z, Magnini VP, Fesenmaier DR (2015) Information technology and consumer behavior in travel and tourism: insights from travel planning using the internet. J Retail Consum Serv (Online), 244-249. 